\title{
LA MOLINERÍA HIDRÁULICA EN EL TERRITORIO VALENCIANO DURANTE LOS SIGLOS XIII-XIX
}

\author{
Tomás Peris Albentosa \\ Historiador
}

\section{RESUMEN}

Gran parte de los esfuerzos de la historiografía que se ocupa del tema se han focalizado en plantear sugestivas hipótesis sobre la función social desarrollada por los molinos en tiempos medievales (tratando de establecer una dicotomía radical entre casales andalusís y feudales) o bien a desvelar los rasgos tecnológicos de las instalaciones (en demasiadas ocasiones se trata, simplemente, de detalladas descripciones o meros catálogos patrimoniales que incluyen los edificios de los que se conserva algún vestigio y las acequias que hacía llegar el agua motriz hasta el artilugio). En contrapartida, tanto la etapa del Antiguo Régimen como los principales rasgos económicos del sector continúan siendo una inmensa incógnita, lo que explica la necesidad de priorizarlos y dedicarles la atención que merecen.

Palabras clave: molinos de agua, aprovechamiento energético de las aguas, acequias, hidrosistemas, estrategias productivas, etapa feudal, Valencia.

\section{ABSTRACT}

Historiography contains many interesting approaches about the function of watermills in medieval societies and their specific technological features. This demonstrates that both the Ancien Régime era and its economic mechanisms are still largely unknown to us today, and justifies greater research into them.

Keywords: watermills, energy use of water, productive strategies, Valencia (Spain), XIII-XIX centuries.

\section{Introducción: la compleja dinámica evolutiva experimentada por el sector}

La trayectoria seguida por la molinería valenciana debe ser contemplada desde una múltiple vertiente que incluye no sólo la edificación de nuevas instalaciones sino también el abandono de aquellas que reunían peores condiciones y las frecuentes reedificaciones de casales, sin olvidar las mudanzas experimentadas en la actividad productiva (variación del número de muelas, alteración del tiempo de trabajo, incremento del salto, etc.). 
Algunas coyunturas especialmente comprometidas provocaron el eclipse y desaparición final de ciertos molinos que acumulaban demasiadas características adversas: estar en un área afectada por un descenso demográfico persistente, sufrir en mayor medida los efectos nocivos de las riadas, originar excesivos desperdicios de caudales, suscitar conflictos enconados, etc. Así, la etapa depresiva que afectó a la comarca de La Plana durante el siglo XV provocó que los artefactos hidráulicos de Castellón se redujeran a los 7 de 1500, la mitad de los que habían llegado a estar activos durante el Cuatrocientos. Los ejemplos de casales molineros arrebatados por la furia de las crecidas fluviales son infinitos, no sólo en las orillas de los principales ríos sino de manera especial en ramblas de enjutos caudales o en humildes barrancos (un magnífico exponente lo constituye la riada extrema del 4 de noviembre de 1864, que arrasó muchos de estos establecimientos en las comarcas de la Costera y la Canal de Navarrés, en el límite de las provincias de Valencia y Alicante). Algunas instalaciones tardías fueron desmanteladas para evitar los alarmantes encontronazos que suscitaban con otros usuarios, como el molino del Fresno, edificado en Burriana en el año 1875 y demolido en 1882 de resultas de las airadas protestas de los regantes perjudicados. Bastantes casales que desaparecieron para siempre compartían los rasgos de carecer de caudales o clientes, al despoblarse el núcleo junto al que se ubicaban. Otros, en cambio, fueron reedificados cuando las circunstancias mejoraron: no pocos de los construidos durante el Setecientos se levantaron sobre casales arruinados siglos atrás (el de Godella, por ejemplo, establecido de nuevo en 1789, era un antiguo molino medieval que todavía figuraba en las Ordenanzas de la acequia de Moncada del año 1658). ${ }^{1}$

En ocasiones, el aumento productivo se consiguió acrecentando el salto, como se hizo en el molino de Casalduch, en el término de Castellón, durante el siglo XVI. Las mudanzas en la regularidad de los caudales hídricos impulsores no podían dejar de afectar a la capacidad productiva: así, sufrir frecuentes sequías o la obligación de tener que respetar largas tandas (el agua podía tardar dos o tres semanas en volver a circular por el tramo de la acequia donde se ubicaba el molino) menguaba de forma drástica el potencial productivo del artefacto... En sentido contrario, resultó habitual añadir muelas durante aquellas coyunturas favorables en las cuales la demanda creció considerablemente. ${ }^{2}$

El sector analizado experimentó numerosos altibajos: hubo fases expansivas, etapas de estabilidad y retrocesos puntuales. El impulso de la molinería hispanomusulmana, en el paso del siglo X al XI (simultánea, por tanto, a la tan evocada revolución del molino en la Europa feudal), acompañó a la génesis de acequias fluviales andalusís alrededor de las principales ciudades valencianas. L. P. Martínez Sanmartín subraya el auténtico impulso hidráulico experimentado, que se materializó en la «construcción de grandes sistemas de riego vinculados a medinas de nueva planta o en proceso de recuperación (casos de Elche, Orihuela o Segorbe)». Las convulsiones que acompañaron a la conquista cristiana (asentamiento de la sociedad feudal, frecuentes episodios bélicos y notables mutaciones en la estructura del poblamiento) ocasionaron una aguda mudanza del mapa molinar. ${ }^{3}$ Mientras que más allá del río Palancia — zona que incluye el norte de la provincia de Valencia y toda la de Castellón - el número de casales se mantuvo estable desde mitad del Trescientos, otras áreas centrales y meridionales del País (en especial las comarcas de la Huerta de

1 Peris, 2000: 275-289; Mesado, 1987: 298; Guinot, 2001: 101 y 207; Bosch, 1866: 304-365.

2 Archivo del Reino de Valencia, Bailía-Letra E, Expediente 243; Guinot, 2001: 113-115.

3 No es fácil cuantificar los molinos hispanomusulmanes. Carmen Barceló aplica al Llibre del Repartiment unos criterios restrictivos y considera que la mayoría de los 103 molinos andalusís se ubicaban alrededor de los grandes núcleos. Por contra, Sergi Selma, otorga mayor importancia a los molinos rurales y eleva el cómputo hasta un total de 385 casales (SELma, 1994). 
Valencia, la Ribera del Júcar, l'Alcoià y la Vall d'Albaida) experimentaron una alza notable que solo se frenó a con la expulsión morisca de 1609. Bastantes lugares aumentaron el número de casales hidráulicos activos en el siglo XIV. Por ejemplo, la revitalización urbana de Elche obligó a edificar nuevos molinos (entre 1305 y 1320 se establecieron 6 artefactos sobre la acequia Mayor). Y la vigorosa expansión demográfica de la ciudad de Valencia obligó a construir diversas instalaciones molineras en la acequia de Moncada durante las postrimerías medievales, mediante las cuales se intentó atender la creciente necesidad de harina que requería la capital del reino. ${ }^{4}$

Al final del Seiscientos y primera mitad del siglo XVIII ya se construyeron bastantes molinos en zonas de realengo - sobre todo en l'Horta de Valencia-; pero la expansión fue todavía selectiva y moderada. La verdadera eclosión global de la molinería valenciana se experimentó en la centuria que va desde 1760 hasta 1850-60, espoleada por diversos factores. Uno fundamental fue el alza demográfica acumulada, que hizo que la demanda de harina se multiplicara. También resultaron básicas la política hidráulica del Despotismo Ilustrado (GIL Olcina, 1992) y la extinción de los monopolios señoriales decretada por las Cortes de Cádiz en el año 1811. Y no podemos olvidar el impacto de relevantes mutaciones económicas afianzadas durante esta fase, como el considerable crecimiento de los perímetros irrigados, la intensa expansión arrocera del Setecientos, la novedosa demanda de papel para encigarrar, etc. El aumento poblacional del siglo XVIII, combinado con las restricciones para establecer nuevos casales, provocó un déficit de moltura que garantizaba obtener jugosos beneficios, lo que incrementó el ansia de los sectores acaudalados por invertir en el sector, adquiriendo molinos activos o construyendo nuevas instalaciones. En aquellas áreas donde el monopolio señorial había sido más efectivo, la expansión molinera fue más vigorosa, como ocurrió en el Camp de Morvedre y las comarcas del Vinalopó. La molienda experimentó un ascenso espectacular alrededor de Sagunto, donde el número de establecimientos, que se había mantenido estable desde las postrimerías medievales, se duplicó entre 1776 y 1861 (los 14 molinos de inicio del siglo XIX ya eran 25 en 1850). Las investigaciones de T. V. Pérez Medina desvelan que el nuevo contexto jurídico existente desde el último tercio de la centuria ilustrada permitió a las élites locales alicantinas alzar decenas de molinos en la cuenca del Vinalopó: los 39 casales harineros activos en el Quinientos aumentaron hasta los 76 de 1836, los batanes textiles pasaron de 8 a 12, se construyeron 7 molinos papeleros y 4 martinetes de esparto... La extraordinaria alza demográfica de la zona (se pasó desde los 1.764 vecinos de 1712 hasta alcanzar los 7.202 a mitad del siglo XIX) resulta clave para entender el espectacular incremento de instalaciones. La fiebre constructora, empujada por la liberalización jurídica y los beneficios que se vislumbraban, acabó culminando en una inédita sobresaturación de la oferta en la mayoría de comarcas valencianas a mitad del Ochocientos. ${ }^{5}$

Aunque la euforia molinar de finales del Antiguo Régimen implicó de manera especial a los señoríos, el proceso fue general en todo el territorio valenciano, como se constata en las comarcas de La Plana castellonense, l'Horta y la Costera (hinterland de la ciudad de Játiva). El crecimiento del Ochocientos fue más limitado en la Huerta de Valencia, debido en parte a que ya se habían construido bastantes molinos durante el siglo XVIII (destaca, sin embargo, la acequia de Rascaña, donde Mangue Alférez documenta 6 nuevos casales, que se añadieron a los 13 existentes; también Paterna duplicó el número de las instalaciones que aprovechaban el caudal de la acequia de Moncada). En la década de 1850 se alcanzó el cenit de la molinería valenciana, momento a partir del que se abandonaron algunos de

4 Martínez, 2005: 391-392; GuinOt, 2003: 157-158.

5 Ferri, 2000: 451-452; Ferri, 2001: 7-10; PÉREZ, 1999; PerIS, 2009. 
los casales hidráulicos que causaban más problemas. Esto significa que combinando los datos de los censos confeccionados por los gobernadores provinciales, la información de Jaubert de Passá y las noticias de Madoz se obtiene una panorámica bastante completa de cual era el perfil productivo y la distribución geográfica de la industria molinera valenciana en su momento de máximo apogeo. ${ }^{6}$

A la hora de explicar la trayectoria constatada, resulta esencial considerar la evolución demográfica y los cambios económicos (roturaciones agrícolas, construcción de nuevas acequias de riego, crisis de la pañería en el siglo XVI, expansión arrocera del XVIII, etc.), sin olvidar relevantes mutaciones sociopolíticas específicas, tales como el debilitamiento del monopolio señorial en el Setecientos y liquidación de esta facultad en el año 1811.

\section{La geografía molinera en tierras valencianas}

\subsection{Una doble red: pequeños molinos rurales y grandes concentraciones de casales}

El sector estudiado siempre tuvo un carácter dual, ya que combinaba infinidad de pequeños molinos, de una o dos muelas, esparcidos por amplias zonas rurales - de una parte-, con importantes concentraciones alrededor de las ciudades, donde abundaron las grandes instalaciones capaces de hacer rodar a un gran número de muelas.

El paradigma de la etapa islámica lo constituyen los pequeños casales que cubrían las necesidades de modestas alquerías, aunque también hubo un reducido número de potentes equipamientos molinares que satisfacían la demanda de la respectiva medina. A mitad del siglo XIX, el sector mantenía este carácter de industria dispersa con una utilidad esencialmente local: de 282 núcleos existentes en la provincia de Valencia, 70 aldeas y pequeños núcleos carecían de molino harinero, y de los 212 pueblos, villas y ciudades que disponían de algún casal molinero, 136 (el 64\%) sólo tenían una o dos pequeñas instalaciones que se limitaban a funcionar para atender las necesidades del vecindario del lugar. ${ }^{7}$

Las grandes acequias fluviales periurbanas, que irrigaban dilatadas huertas en los llanos de inundación del litoral valenciano, originaron notables concentraciones molineras que conseguían atender la demanda de la respectiva urbe así como de algunas áreas deficitarias no demasiado lejanas. La Huerta de Valencia constituye el mejor ejemplo. Martínez Sanmartín menciona como la Balansiya hispanomusulmana generó un cinturón de molinos de gran capacidad productiva que aprovechaban el caudal que circulaba por las acequias que sangraban el Turia, en especial la de Rovella y los canales secundarios — brazos o braçalsde Algirós (acequia de Mestalla) y Alaxar (Rascaña). El enorme auge demográfico de la ciudad de Valencia durante el siglo XV se resolvió aumentando la capacidad molinera de la acequia de Moncada y tratando de garantizar que llegara a las siete acequias de la Vega el agua necesaria para que las muelas pudieran siguieran rodando incluso en momentos de fuerte estiaje. Este tradicional protagonismo molinero de l'Horta en el contexto general valenciano incluso se acentuó durante los siglos XVIII y XIX, potenciado por corrientes comerciales de largo alcance. Pero más relevante aún que la pléyade de casales que llegaron a existir en las acequias que irrigaban la huerta que rodea a la capital (la Junta de

6 Mangue, 2000: 411; Ferri, 2001: 459; Guinot, 1999: 71.

7 En la provincia de Castellón, de un total de 83 núcleos que disponían de molino (otros 66 no consta que lo tuvieran), en 38 pueblos sólo trabajaba uno o dos pequeños casales, lo que representa el $46 \%$ de la muestra analizada. En Alicante había 80 pueblos sin molino (53\%), y de los que sí lo tenían, 36 únicamente disponían de uno o dos pequeños casales, cifra que representa la mitad de las instalaciones de las que consta registraban alguna actividad de molienda (MADOZ, 1982; PERIS, 2009, apéndices). 
Comercio calculaba que allí funcionaban 158 de los 473 molinos que había censados en la provincia a mitad del Ochocientos), es la enorme producción conseguida por una minoría de grandes instalaciones hidráulicas. Según Marc Ferri, el molino de Peña, ubicado en el término de Paterna, producía 8.000 fanegas anuales en 1849, «más que los 18 molinos de Ontinyent juntos». Idéntica situación se repetía, a una escala menor, alrededor de otras ciudades y villas, como Játiva, Orihuela, Castellón, Alzira, Sagunto, Elche, Alcoi, Liria, Segorbe, Crevillente, Almazora, Burriana, etc. ${ }^{8}$

En otros casos, el agrupamiento de ingenios respondía a factores económicos. Por ejemplo, la Vall d'Albaida y l'Alcoià constituyeron auténticas regiones industriales desde el inicio del Quinientos: en cinco villas reales - entre ellas Alcoi- llegaron a concentrarse 83 instalaciones hidráulicas. Mira Jódar informa que, además de numerosos molinos harineros, en el año 1530 trabajaban en estas dos comarcas 33 batanes y 8 casales dedicados a diversas actividades productivas. El jurista ilustrado Vicente Branchat recoge tanto la génesis de nuevos molinos de papel como la reconversión de antiguos batanes textiles en establecimientos papeleros, un proceso que se inició alrededor de 1750 y se intensificó desde 1779. T. V. Pérez Medina, por su parte, informa que en la cuenca del Vinalopó se produjo, en paralelo al considerable incremento de molinos harineros, un notable aumento del número de batanes, instalaciones papeleras, martinetes de esparto, etc. ${ }^{9}$

A la hora de explicar la abundancia de infraestructuras que aprovechaban la energía hidráulica en unas zonas y déficit que se sufría en otras,${ }^{10}$ hay que combinar factores demográficos (densidad de población y potencia del influjo urbano) con otros geográficos (disponibilidad de caudales) y económicos (estructura agraria, flujos comerciales, etc.). Los nexos entre poblamiento y mapa molinar ya se advierten en época islámica, cuando buena parte de los casales se ubicaban cerca de la alquería a la que debían servir. Si los principales perímetros irrigados del litoral, como los existentes en las comarcas de Horta, Ribera del Júcar, la Plana, etc., fueron las zonas donde mayor número de casales llegaron a funcionar, no fue únicamente por el agua que fluía por las acequias sino también por la gran demanda derivada de la alta densidad de población que se alcanzó en estas áreas de agricultura tan intensiva. La proximidad a los núcleos donde residían los parroquianos proporcionaba comodidad y permitía reducir los costes de transporte, de manera que siempre se procuró acercar todo lo posible los molinos a los principales centros de consumo que, además, ejercían como activos mercados comarcales y regionales. ${ }^{11}$

Los factores geográficos, en especial la disponibilidad de agua, también estuvieron presentes, pero cumplieron un papel bastante más secundario del que se les podría suponer de antemano. Ello se explica porque las alternativas técnicas disponibles permitían trabajar tanto con los escuálidos caudales procedentes de alguna fuente (acumulándolos previamente en una balsa y aprovechando la energía a presión obtenida en los cubos), el modesto flujo de un barranco (buscando el lugar más idóneo) o con la abundante corriente que circulaba por los canales que captaban la agua de los principales ríos (no era necesario, en estos casos, construir ninguna balsa ni disponer de gran salto).

8 Martínez, 2005: 390-391; GLICK, 1988: 149-150; Ferri, 2000: 458-464; Peris, 1992a: 151-153.

9 Mira, 2000: 228-239; PÉRez, 2000: 366-384; BrAnChat, 1784, I: 257-258, 277-279, 290-292. También hubo varios molinares en las comarcas castellonenses del Maestrazgo y Els Ports (PerIs, 2009).

10 Resulta de lo más elocuente que en las áridas tierras alicantinas funcionaran 56 molinos de viento a mitad del Ochocientos para tratar de suplir el déficit de molinos de agua (MAdoz, 1982; Peris, 2009).

11 La proximidad del molino todavía era más recomendable cuando los caudales que proporcionaban la energía eran irregulares y la molienda discontinúa, ya que no era conveniente perder tiempo en un largo viaje a causa del peligro que el artilugio permaneciera inactivo o bien hubiera demasiado parroquianos esperando y no pudiera obtenerse turno para moler, inconvenientes que no se sufrían cuando la instalación funcionaba en las afueras de la población donde se residía. 
Más importante de cara a explicar el mapa de la molinería valenciana resultan los aspectos económicos en general y los flujos mercantiles del final del Antiguo Régimen en particular. Un ejemplo elocuente se percibe al constatar como la construcción de la Real Fábrica de Enguera, en la segunda mitad del Setecientos, estimuló la aparición de numerosos casales para batanar lana en la zona cercana de Anna-Estubeny, donde se disponía de abundantes corrientes de agua y de saltos apropiados. Y no se puede entender la existencia de la mayoría de instalaciones papeleras en tierras valencianas al final del siglo XVIII sin tener presente el encargo de la Hacienda Real de producir papel de encigarrar para todos los territorios de la monarquía hispana. La tardía mejora de los transportes también contribuye a explicar la abundancia de molinos a los largo de los itinerarios por los que se producía la llegada de trigo foráneo hacia los principales núcleos valencianos. M. Ferri señala la profusión de casales en las comarcas que eran ruta de paso del trigo castellano o aragonés, en tránsito hacia la ciudad de Valencia, a mitad del Ochocientos: «La entrada del trigo de la Mancha 'baja' se daría tanto por la Costera (donde la ruta Moixent-Canals-Xàtiva, con seis, tres y 11 molinos [... era] otra concentración importante de molinos), como por la Vall d'Albaida, con los 12 molinos de Bocairent o los nueve de Albaida. En cambio el trigo de la Mancha 'alta' debía buscar la Huerta atravesando la Hoya de Buñol, donde la molienda aparece bastante repartida entre [...] Buñol, Cheste, Chiva y Turís». ${ }^{12}$

\subsection{Una amplísima mayoría de molinos integrados en la red de canales de riego}

Los criterios aplicados para decidir entre los posibles emplazamientos (limitar el peligro de riadas, proximidad a los parroquianos, cautelas para minimizar los conflictos con otros usuarios del agua) explican que casi todos los casales funcionaran en acequias concebidas con el objetivo prioritario de regar los campos.

Siempre existió una minoría de casales fuera de los perímetros irrigados. Ya los había junto a los principales cursos fluviales al final de la etapa musulmana; pero no precisamente sobre barcas, sino edificados en el cajero de los principales ríos, que derivaban caudales mediante acequias exclusivas y con muelas impulsadas por ruedas horizontales, como la docena de casales que llegaron a funcionar a orillas del Júcar, en la comarca de la Ribera Baja, y algunos otros documentados junto al lecho de los ríos Mijares y Segura. No obstante, cada vez resultaron menos necesarios, conforme se fueron construyendo acequias que permitían edificar nuevos molinos en emplazamientos idóneos (la mayoría se fueron abandonaron tras las peores riadas). Y en ciertas áreas montañosas surgieron conjuntos de instalaciones industriales que aprovechaban el caudal de arroyos y barrancos: algunos de estos «molinars» contribuyeron a la expansión textil bajomedieval (como los del río de La Cenia, los de la cuenca alta del Vinalopó y los que operaron en las inmediaciones de Alcoi), pero la mayoría de estos complejos de aprovechamiento energético de las aguas cuajaron o adquirieron mayor relevancia a partir de mediados del siglo XVIII. ${ }^{13}$

No hay duda alguna que una aplastante mayoría de casales, en especial los más potentes, funcionaron integrados en acequias de riego sin observar la supuesta pauta de molinos «hispanomusulmanes» o andalusíes al final del sistema hidráulico y «feudales» en la cabecera. En los macrosistemas valencianos se constata una gran aleatoriedad en lo que se refiere a la posición relativa de molinos y tierras regadas. Hace unos 20 años, el geógrafo V. Rosselló Verger ya señaló que los datos obtenidos en la Huerta de Valencia contradecían la tesis de

12 RIBES, 1995: 104-105; FERRI, 2000: 463-464.

13 Selma, 2000: 105-108, 141-143 y 152-153; Glick-Martínez, 2000: 86-87; Furió-Martínez, 1994 : 575-586; GuINOT, 2001: 137-138 y 175-189; GuINOT, 2000: 196-198, 213-217 у 220-221; CAVANILLEs: 1795-97, I, 81-82, II, 192-195; PÉREZ, 1999: 91-92; MirA, 2000: 241-254. 
Miquel Barceló, ya que tanto en la época musulmana como durante la etapa feudal hubo instalaciones que aprovechaban la fuerza motriz de las aguas en la cabecera de los canales de riego, al final del hidrosistema y no faltaban molinos en posiciones intermedias (RosseLLÓ, 1993: 515-522). Tres años después, yo mismo pude constatar como en la acequia Real de Alzira, construida por los feudales durante la segunda mitad del siglo XIII, los casales molineros se repartían de manera contingente por todo el perímetro irrigado:

El estudio [...] de los molinos de la Ribera [...] ha permitido constatar que la posición relativa de los molinos dentro los grandes sistemas de aprovechamiento hidráulico no era nada significativa. El postulado de Barceló relativo a la jerarquía espacial del molino y el regadío dentro del sistema como indicativa del tipo de sociedad que diseñó y construyó el sistema hidráulico tampoco rige en las grandes acequias fluviales de la comarca. El concepto «molino de cierre / molino de inicio de sistema» adquiere en los macrosistemas [...] un sentido demasiado relativo. La ubicación [...] no sólo se fijaba en función de no alterar [...] la distribución de las aguas de riego, sino que de otros factores muy relevantes eran la regularidad de los caudales que impulsaban el molino, la proximidad al núcleo [...] donde residía la clientela o evitar emplazamientos demasiado negativos de cara a las endémicas riadas. (PerIs, 2000: 298-303)

Es importante señalar que desde fechas bien tempranas se configuraron áreas especializadas en el aprovechamiento energético de las aguas en las cabeceras de las principales acequias - séquia mare - así como en el primer tramo de algunos canales secundarios - brazales - . Los molinos tendieron a emplazarse en aquellos puntos donde el caudal era el abundante y continuo. La plétora de casales en los primeros tramos de las acequias de la Huerta andalusí ha estado constatada por L. P. Martínez a partir de los datos que proporciona el Llibre del Repartiment. Y la misma preferencia de ubicarse cerca del azud, se observa en la acequia de Moncada: instalaciones con numerosas muelas funcionaron en el segundo tramo, denominado significativamente «de los Molinos», allí donde la corriente era abundante y rápida - las áreas regadas se ubican aguas abajo - , de manera que garantizaba una explotación energética intensa y sostenida. El mismo criterio que habían empleado las comunidades hispanomusulmanas, hacer de la cabecera del sistema punto prioritario donde ubicar molinos (cosa que no implicaba ninguna preferencia en el uso de los caudales), siguió aplicándose siglos después por la sociedad feudal, como patentizan los ejemplos de l'Horta, Camp d'Elx, La Plana, la Ribera del Júcar, etc. Siempre que fue posible, se mantuvo la tendencia a agrupar los molinos cerca de los consumidores, tanto por razones de comodidad como propiciar una mayor vigilancia, minimizando de esta forma los conflictos con los regantes. Se originaron así brazales donde la molienda consiguió máxima relevancia. El ejemplo mejor estudiado lo constituye la Huerta de Valencia: tanto el brazo de Alaxar (acequia de Rovella) como los de Algirós y Petra (Mestalla) han estado calificados como «brazos de molinos», a causa de la batería de casales ubicados en el segmento inicial de cada canal secundario, donde el caudal circulaba con gran velocidad, gracias a la fuerte pendiente de la acequia, y el conducto «estaba nada o poco disminuido por las sangrías de los regantes». ${ }^{14}$

Los casales también abundaron en los principales hidrosistemas, tras algún partidor (eso si, a la distancia necesaria para que el reflujo de las aguas originado por el molino

14 Peris, 2000: 298-303; Peris, 1992a: 142-157; Guinot, 2003: 171; Martínez, 2000: 383-392; GLiCKMartínez, 2000: 91-95; PÉREZ, 1999: 91 y 60; Guinot, 2001: 131-141 y 160-161; Sendra, 1998: 72; Mangue, 2000: 418-425. 
— regolf - no alterara el prorrateo de las aguas, minimizando los encontronazos con otros usuarios) o poco después del punto donde confluían dos conducciones que sumaban los respectivos caudales. Una última modalidad eran los molinos de cierre de sistema y los que aprovechaban las escorredurías embalsadas en las acequias (escorrims). La tendencia a ubicar casales al final de la red, de manera que aprovecharan el agua que no se necesitaba para regar, cuando se evacuaba a través de escorredores, no fue peculiar de la etapa andalusí; bien al contrario, se mantuvo durante todas las centurias estudiadas, en especial desde finales del Setecientos. Esta modalidad de casal existió en todos los macrosistemas del litoral valenciano (Villareal, Burriana, Cullera, áreas extremales de Moncada o Rascaña, etc.), ya que lograba compensar los inconvenientes derivados de la irregularidad de caudales impulsores, que únicamente permitían moler durante cortas temporadas, con la ventaja de la proximidad a los pueblos de la zona. ${ }^{15}$

\section{Rasgos económicos y estrategias productivas adoptadas en el sector molinero}

\subsection{Las actividades a las que se aplicaba la energía: la contundente hegemonía de las instalaciones harineras}

El casal harinero de rueda horizontal (rodezno), siempre fue predominante. Ya lo era en tiempos medievales. Y siguió siéndolo a mitad del siglo XIX, cuando los cerca de 600 molinos que funcionaban en la provincia de Valencia en 1847 (de los cuales 72 eran mixtos, harineros y arroceros) representaban el $91 \%$ de la tasación fiscal del conjunto de aprovechamientos de energía hidráulica (el resto incluía 16 instalaciones arroceras, 33 batanes, 7 prensas textiles, 21 casales papeleros, algunas almazaras, martinetes metalúrgicos y de esparto, así como unos pocos molinos de yeso, pólvora, etc.). ${ }^{16}$ Podemos estar seguros, pues, que estudiando el subsector harinero conseguimos una imagen representativa, ya que el resto de aprovechamientos energéticos de las aguas constituían, desde el punto de mira económico, actividades netamente secundarias. ${ }^{17}$

Pese a ello, en contraste con las prolijas descripciones de los edificios, no sabemos mucho de los aspectos económicos y la retribución de este servicio, más allá de alguna norma genérica. Se tiende a presuponer el servicio de triturar cereales se pagaba con una parte del producto, la maquila, y raramente en dinero. Un fuero de Jaime I prescribía «muelan el trigo a decimosexta, e cebada a trezena, e panizo e mijo a decimoquinta. E [...] que por mayor precio non muelan, mas por menor pueden». ${ }^{18}$ Pero este precepto hubo de adaptarse a situaciones muy heterogéneas. Cada vez que la oferta resultaba excesiva, se ponían en

15 Archivo del Reino de Valencia, Bailía, Letra E, expediente 1.229; SElma, 2000: 136; PÉrez, 1999: 3945; Guinot, 2003: 162-165, 175 y 185-186; Castillo, 1997: 60; Mangue, 2000: 434 y 440-445; Guinot, 2001: 106-108, 113, 124, 138, 151, 162-163 y 206-207; GuINOt, 1999: 33 y 157-158; Peris, 1992a: 151-153.

16 Madoz, 1982; Expediente de remisión de las acequias y molinos que existen en [...] la provinciano de Valencia, de 1847 (Archivo de la Diputación Provincial de Valencia, E. 3.1, caja 75, legajo 75-76, expediente 1.344); FERRI, 2000: 451-482. El Expediente de 1847 explicita 488 molinos harineros, pero hay que tener presente que 42 de los 281 pueblos no respondieron a la encuesta. Para la provincia de Castelló en 1848, disponemos del censo del gobernador (Datos estadísticos relativos a la provincia de Castellón, reunidos durante el Gobierno del Sr. D. Ramón de Campoamor. 1850, Archivo de Hacienda de Castellón, manuscrito).

17 El subsector textil había menguado en el siglo XIX respeto del máximo esplendor alcanzado en época medieval, pero este eclipse resultó compensado por la emergencia de la industria del papel, basada también en la energía hidráulica, durante la segunda mitad del Setecientos.

18 Fori Regni Valentiae..., folio 236. Pere J. Taraçona recogió que «Los moliners dehuen pendre lo forment a pes, y tornar la farina a pes, pagant lo que faltara, y sia lo pes franch [...]. Y prenguen per la moltura, del forment la setzena part, del paniz y mill la quincena part, del ordi la tretzena part, y no més, mas menys si; y no la prenguen en diners, sots la pena de cent florins» (TARAÇONA, 1580: 167-168). 
marcha diversas presiones para intentar reducir la tasa: así, en respuesta a ellas, los molineros de Villareal se juramentaron, al inicio del Quinientos, para no trabajar por menos de los tres almudes por cahíz que prescribían los Fueros. En Sagunto, desde el año 1605, la maquila del trigo (1/16) fue la mitad de la exigida para el resto de granos (1/8). Y la tasa contemplada en las abundantes cartas pueblas valencianas posteriores a la expulsión morisca de 1609 fluctuó desde la cuota estándar (1/16 en Beselga-Estivella o Elda) hasta otras muy bajas (1/24 en Gaibiel e incluso 1/48 en Albalat-Segart). En cambio, los vasallos del monasterio castellonense de Benifassà, se veían constreñidos a pagar en 1701, «por molerles un cahíz de trigo cogido en la Tenencia 6 almudes [... es decir, 1/8] y del que bajaban de Morella o Aragón 4 almudes [1/12]». ${ }^{19}$ Las referencias a remuneraciones en dinero por moler granos suelen ser tardías, pero no faltan antes la Nueva Planta borbónica (1707): así, el duque de Gandía revisó las tasas exigidas por este servicio en la comarca de la Safor el 22 de julio de 1598, dejándolas en 3 sueldos por cahíz para los vecinos de Oliva, mientras que el resto de usuarios deberían negociar el precio con los respectivos molineros. E. Císcar Pallarés informa que en la Valldigna se pagaban, en el año 1602, 4 sueldos por cada carga de arroz que se blanqueaba en los molinos de la zona. De la inicial homogeneidad se pasó, pues, a una situación diversa: hubo molinos maquileros que cobraban una parte del grano llevado a moler - seguramente la mayoría - y otros que retribuían el servicio en metálico, lo que parece ser que permitía una mayor flexibilidad (subir gradualmente el precio en momentos de aguas escasas y reducirlo poco a poco durante los meses de caudal abundante). ${ }^{20}$

\subsection{El contraste entre la capacidad productiva potencial y la actividad efectiva: irregu- laridad de caudales y tendencia estacional del aprovechamiento de las instalaciones}

Otoño era con mucho la temporada de mayor trabajo de molienda a causa de la incidencia de varios factores. Los más importantes eran que la temperatura fresca ayudaba a conservar la harina y que la abundancia de lluvias hacía crecer las corrientes fluviales cuando menos necesario resultaba regar unos campos empapados de sazón.

Debido a la tan irregular pluviometría mediterránea, tres de cada cuatro molinos dejaban de trabajar durante el verano debido a la combinación de mengua de caudales y urgencias para irrigar las tierras, dada la contundente subsidiariedad de la molienda respecto al riego de los campos. Esto ocurría en mesosistemas mal dotados hídricamente, pero también incluso en las huertas más importantes. El molino de Santa María, en Gandía, permanecía inactivo durante la temporada comprendida entre la plantación del arroz y la siega de este cereal. Acerca de la acequia de Mislata se decía, en 1776, que «no siendo perenne y abundante de aguas el [... Turia], las que regularmente trae en tiempos de verano [...] no son bastantes para el riego»; de manera que «cuando ésta [agua] falta, más de dos terceras partes de los molinos quedan sin moler». De las cinco muelas autorizadas al casal que F. Campos poseía en Quart, el año 1831, solo llegaron a instalarse dos, de las cuales «sólo corre una»; la aparente desidia se explica por la falta de caudales impulsores, puesto que en las frecuentes ocasiones en que «quitan el agua [...] para el riego [...], se halla parado el artefacto». Mestalla y Rascaña sufrían fuertes estiajes durante el verano, que complicaban o llegaban a impedir la molienda. Incluso las instalaciones que funcionaban cerca del caudaloso Júcar debieron abrir pasos - goles o gargantas - en los azudes, desde 1635, para dejar pasar buena parte de la corriente durante la temporada en que era vital regar los arrozales de la

19 El cahíz de trigo equivalía a 201 litros y se subdividía en 12 barchillas o 48 almudes.

20 Doñate, 1990: 110; Ferri, 2000: 455; Císcar, 1977: 231; Arasa, Forcadell y Michavila, 2000: 400; MAYANs, 1976: 326; CísCAR, 1997: 66-67; R. Planes informa que fue habitual pagar en dinero en los molinos reales de Barcelona y que el precio se encarecía en tiempo de carestía de caudales hídricos (PlANEs, 2008: 242-243). 
Ribera Baja (desde el primero de mayo hasta inicio de octubre). Los efectos adversos de los estiajes resultaron especialmente intensos en las áridas comarcas alicantinas: así, por ejemplo, los molinos de Monforte - en la cuenca del Vinalopó- únicamente podían trabajar durante el invierno, ya que el resto del año no les llegaba el agua suficiente. ${ }^{21}$

Cuadro 1

ESTACIONALIDAD DE LOS MOLINOS HARINEROS Y ARROCEROS DE LA PROVINCIA DE VALENCIA (1849)

\begin{tabular}{|c|c|c|c|c|c|c|}
\hline \multirow{3}{*}{$\begin{array}{c}\text { Tipo de casal molinero } \\
\text { y temporada } \\
\text { de actividad }\end{array}$} & \multirow{3}{*}{$\begin{array}{l}\text { Número } \\
\text { de } \\
\text { casales }\end{array}$} & \multirow{2}{*}{\multicolumn{2}{|c|}{ Muelas }} & \multicolumn{3}{|c|}{ Imponible fiscal } \\
\hline & & & & \multirow{2}{*}{$\begin{array}{l}\text { Tasación } \\
\text { (reales) }\end{array}$} & \multicolumn{2}{|c|}{$\%$} \\
\hline & & $\mathbf{N}^{\circ}$ & $\%$ & & Molinos & Total \\
\hline Trabaja durante todo el año & 127 & 169 & 27,8 & 143.500 & 40,7 & 36,9 \\
\hline Trabaja entre 6 y $12 \mathrm{~m}$ & 157 & 183 & 30,1 & 107.800 & 30,6 & 27,7 \\
\hline Id. entre 3 y 6 meses & 113 & 163 & 26,8 & 73.200 & 20,8 & 18,8 \\
\hline Id. menos de 3 meses & 83 & 93 & 15,3 & 27.900 & 7,9 & 7,2 \\
\hline $\begin{array}{l}\text { Total de molinos harineros } \\
\text { y arroceros }\end{array}$ & 480 & 608 & 100,0 & 352.400 & 100,0 & 90,7 \\
\hline Batanes, papeleros, etc. & 59 & -- & -- & 36.000 & - & 9,3 \\
\hline \multicolumn{4}{|c|}{ Total aprovechamientos energéticos provincia de Valencia } & 388.400 & -- & 100,0 \\
\hline
\end{tabular}

Fuente: Madoz, Diccionario..., II, p. 229-231. Elaboración propia.

Disponemos de estadísticas sobre la estacionalidad de los molinos harineros de la provincia de Valencia en 1849: cuatro de cada diez rodaban menos de la mitad del año (el 17\% no llegaban a estar activos ni siquiera tres meses $)^{22}$ y tan sólo una cuarta parte disponían de caudales que permitieran trabajar - al menos en teoría - durante todo el año, circunstancia que se refleja en el superior imponible fiscal que se les atribuía (sumaban 169 muelas, el 28\%, pero resultaban tasados en 143.500 reales, es decir, el $41 \%$ del total).

La imposibilidad de moler durante el verano o la restricción de limitarse a trabajar únicamente durante el invierno eran pautas vigentes en toda la geografía valenciana. El molino de Bélgida (en el partido judicial de Albaida) elaboraba harina sólo tres meses «durante el invierno, pues en el estío carece de agua». Ninguno de los 7 molinos de Sagunto, impulsados por el río Palancia, podía trabajar en verano porque no disponían de suficiente corriente. Muchos casales valencianos fueron etiquetados como de escorrims, es decir, que no tenían reconocida ninguna dotación hídrica y se limitaban a rodar con el agua que quedaba embalsada en las acequia de riego o con la sobrante tras cubrir las necesidades agrícolas. De este tipo eran los dos casales de Rótova (en la comarca de la

21 Expediente de remisión de las acequias y molinos..., Archivo de la Diputación Provincial de Valencia, E. 3.1., legajo 75-76, 1344; Archivo del Reino de Valencia, sección Bailía, letra E 2, expediente 956, ff. 148v-149v y 154v; Bailía, letra E, expediente 1101, apéndice, ff. 25 y 34v (también núm. 606, 1767, f. 1v); PérEz, 1999.

22 El de Aielo de Rugat apenas trabajaba 3 meses por falta de agua, el molino de Bèlgida «únicamente se mueve durante el invierno, pues en el estío carece de agua», como el de Benisuera, el de Camilles -Castelló de Rugat - empleaba aguas sobrantes durante menos de 3 meses, el de Rugat tan sólo trabajaba 3 meses y el molino Nuevo, del mismo pueblo, se limitaba a emplear los sobrantes del anterior, los 2 casales de Rótova eran «de invierno, porque toda el agua se gasta para el riego en verano» (Expediente de remisión...). 


\section{Cuadro 2}

VALOR ECONÓMICO DE LOS CASALES EXISTENTES EN LAS ACEQUIAS DEL CURSO BAJO DEL JÚCAR Y ESTACIONALIDAD DE LA ACTIVIDAD MOLINERA POR EFECTO DE LAS VARIACIONES DE CAUDAL (1860)

\begin{tabular}{|c|c|c|c|c|c|c|c|c|}
\hline \multirow{3}{*}{ Acequia } & \multicolumn{2}{|c|}{ Tierras } & \multirow{3}{*}{$\begin{array}{c}\text { Acequias } \\
\begin{array}{c}\text { Valor } \\
\text { (miles de } \\
\text { reales) }\end{array}\end{array}$} & \multicolumn{5}{|c|}{ Molinos } \\
\hline & \multirow{2}{*}{$\begin{array}{l}\text { Superficie } \\
\text { irrigada } \\
\text { (hectáreas) }\end{array}$} & \multirow{2}{*}{$\begin{array}{c}\text { Valor } \\
\text { (miles de } \\
\text { reales) }\end{array}$} & & \multirow[t]{2}{*}{$\mathbf{N}^{0}$} & \multicolumn{2}{|c|}{$\begin{array}{l}\text { Muelas activas } \\
\text { caudal ordinario }\end{array}$} & \multirow{2}{*}{$\begin{array}{c}\text { Muelas } \\
\text { caudal } \\
\text { extraordin. }\end{array}$} & \multirow{2}{*}{$\begin{array}{c}\text { Valor } \\
\text { (miles de } \\
\text { reales) }\end{array}$} \\
\hline & & & & & $\mathbf{N}^{0}$ & $\%$ & & \\
\hline Real Júcar & 13.844 & 199.252 & 88.680 & 44 & 88 & 69,8 & 126 & 9.020 \\
\hline Sueca & 6.415 & 92.373 & 15.715 & 9 & 9 & 47,3 & 19 & 1.439 \\
\hline Carcaixent & 1.325 & 19.078 & 10.026 & 4 & 12 & 100,0 & 12 & 464 \\
\hline Cullera & 3.370 & 48.525 & 15.212 & 4 & 14 & 82,3 & 17 & 2.1000 \\
\hline Corbera & 1.542 & 22.197 & 2.573 & 3 & 7 & 87,5 & 8 & 3996 \\
\hline Escalona & 1.029 & 14.827 & 11.684 & 2 & 4 & 50,0 & 8 & 480 \\
\hline Sumacàrcer & 154 & 2.226 & 125 & 2 & 4 & 100,0 & 4 & 120 \\
\hline Antella & 148 & 2.132 & 704 & 2 & 5 & 100,0 & 5 & 70 \\
\hline Total Ribera & 27.827 & 400.713 & 144.722 & 70 & 143 & 71,8 & 199 & 14.092 \\
\hline
\end{tabular}

Fuente: Peris Albentosa: «Aigua i molins en un macrosistema fluvial valencià...», p. 348.

Safor, caudales del río Vernissa) que exclusivamente molían en invierno "puesto que toda el agua se gasta para el riego en verano». ${ }^{23} \mathrm{La}$ irregularidad llegaba a ser extrema en los molinos denominados de revinguda - de riadas - , ya que algunos casales tan sólo eran capaces de moler cereales cuando las lluvias hacían circular agua por los lechos de las casi siempre resecas ramblas. Madoz informa que en el partido de San Mateo, en el interior de la provincia de Castellón, había «algunos molinos harineros que muelen en tiempos de lluvias y avenidas, por estar secos generalmente sus cauces». El casal existente en el valle de Laguar, en la provincia de Alicante, «solo muele en las avenidas» que le llegaban por el barranco tras caer intensos aguaceros; y los dos molinos movidos por el río Gallinera, en el término de Pego, "sólo muelen en los años de abundantes lluvias» pero no en los años de pluviometría normal. Esto no ocurría exclusivamente en pequeños barrancos y las ramblas más secas, sino incluso en afluentes de cierta entidad, como los ríos Magro o Albaida, relevantes tributarios del Júcar. ${ }^{24}$

La capacidad potencial de las 199 muelas movidas por acequias del Júcar - el río valenciano más caudaloso y menos afectado por estiajes - era, en 1860, del orden de entre 174.000 y 261.000 toneladas anuales. Lógicamente, nunca se llegó, sin embargo, a alcanzar

23 El molino de Cotes - río Sallent - trabajaba poco a causa de la escasa agua que le dejaba el regadío. El de Real de Montroi, impulsado con aguas del Magro, sólo funcionaba durante 4 o 5 meses debido a «estar detrás de la huerta situado». Los 5 molinos de Navarrés — partido judicial de Enguera - se mantenían activos durante poco tiempo a causa de los escasos caudales de fuentes que quedaban tras irrigar la huerta. El de Llaurí se limitaba a emplear sobrantes de riego...

24 También tres de los cinco molinos existentes a Alboraia - Huerta de Valencia - a mitad del Ochocientos sólo podían funcionar con el agua de las crecidas fluviales. 
estas cifras, ya que las instalaciones no molturaban todos los días del año ${ }^{25}$ ni a todas las horas del día y la noche. Las acequias de Sumacárcel, Antella y Carcaixent podían impulsar las muelas harineras y arroceras durante la mayor parte del año. El contraste de actividad entre fases de caudal ordinario y extraordinario todavía resulta moderado en las acequias de Corbera y Cullera. Por contra, la mayor parte del tiempo sólo funcionaban 4 de las 8 muelas de la acequia de Escalona y 9 de las 19 existentes en Sueca. La acequia Real del Júcar ocupa una posición intermedia: en momentos de caudal ordinario rodaban entre 56 y 88 de las 126 muelas existentes en este canal, apercibiéndose mayor penuria conforme avanza el siglo XIX, un problema que afectó en mayor medida a los casales ubicados en la Segunda Sección del principal hidrosistema valenciano. ${ }^{26}$

Los problemas apuntados se acentuaban durante los años de fuerte sequía y en las áreas deficitarias, conforme se fueron generalizando las tandas de riego. Cuando el caudal captado no se subdividía (distribuyéndolo por los diversos canales secundarios en proporción a la superficie a regar por cada uno de ellos), sino que circulaba alternativamente por unos brazales u otros - tandas - , los molinos que no estaban ubicados en cabecera del hidrosistema únicamente podían funcionar aquellos días en que correspondía regar a la zona donde estaban emplazados. M. Ferri informa que el fin momentáneo de las tandas en la acequia Mayor de Sagunto (1800) provocó un desmesurado interés por edificar casales en una zona no muy distante de la ciudad de Valencia, y como, en sentido contrario, reintroducir el tandeo resultó desastroso para los molinos inferiores (jussans), que tan sólo pudieron mantenerse activos desde entonces un par de días por semana (en 1852, el de Sacanet estaba «parado tres años: sólo recibía agua el día de tanda quincenal [...] y entonces la concentración de caudales lo inundaba hasta inutilizarlo»). Los ejemplos de casales que disponían de agua durante uno o dos días cada semana podrían multiplicarse, tanto en las grandes huertas fluviales como en humildes mesosistemes de montaña. En la acequia Mayor de Castellón, los casales funcionaban un par de días (el molino Romera lo hacía desde la puesta del sol del lunes hasta el mediodía del miércoles). Los casales molineros de Museros, El Puig y Puzol ejemplifican las limitaciones operativas que afectaban a los artefactos de aguas abajo, ya que, aunque estaban dentro de un perímetro particularmente bien dotado de caudales hídricos - la acequia de Moncada - sus muelas solo conseguían rodar dos días a la semana. Algunos casales se vieron limitados a trabajar en el corto intervalo en que circulaba la tanda de riego, pero únicamente durante horario nocturno, como ocurría en Simat, en la subcomarca de la Valldigna. ${ }^{27}$

Una gran flexibilidad permitía, conforme menguaba el caudal, hacer paradas en la acequia, reducir las muelas activas o moler a balsadas. Había instalaciones que siempre molturaban así y otras que se limitaban a hacerlo durante los años en que se sufría penuria de aguas. Las instalaciones impulsadas mediante el agua de fuentes sólo podían operar durante un breve lapsus de tiempo, ya que debían esperar a que la balsa volviera a llenarse para reiniciar su trabajo: es el caso del molino de Godelleta - partido de Chiva- , que funcionaba menos de 6 horas diarias. Los años en que el agua menguaba, bastantes instalaciones molinares se veían obligadas a adoptar este sistema: en los casales harineros

25 Muchos molinos paralizaban su actividad mientras se realizaba la limpieza anual de los canales - que en ocasiones duraba más de un mes - y mientras se restablecía la red hidráulica después de las endémicas riadas. Un fuero preceptuaba el descanso dominical de los molineros: «no molguen del dissapte pús les vespres sonaran tro al dia del diumenge que les vespres hauran sonat. E si ho faran, perden lo blat que hauran haut aquell dia per moltura».

26 Peris, 2000: 344-345; Archivo de la Acequia Real del Júcar, legajo 119, nº 3; legajo 31, $\mathrm{n}^{\circ} 15$ y legajo $34, \mathrm{n}^{\circ} 6$, f. 3 .

27 Ferri, 2001: 9-10; GuINOt, 2001: 104-105 y 107; Guinot, 1999: 163-164 y 177-181; Expediente... 
de Banyeres de Mariola «los años secos no pueden moler de continuo, sí solo a balsadas, esto es, dejando llenar el cubo [...] y moliendo únicamente el corto tiempo que tarde en baciarse aquel repuesto de agua, por no ser suficiente la que corre para dar movimiento a la muela». Precisamente, las máquinas de vapor empezaron a aplicarse en el sector de la molienda a mitad del Ochocientos con el objetivo que los casales urbanos que gozaban de una gran demanda, y que sufrían inoportunos paros debido a la falta de agua, pudieran mantener una actividad tan continuada como lo requirieran las peticiones de los usuarios. ${ }^{28}$

El déficit coyuntural de servicios molineros obligó con frecuencia a desplazarse a otros lugares para transformar los granos en harina. La ciudad de Valencia ya sufrió este quebradero de cabeza al inicio del siglo XV, cuando los ediles del municipio enviaron trigo a Paterna y otras poblaciones — algunas distantes más de 30 kilómetros - para molerlo. El mismo problema se padeció en Elche en el año 1423, cuando los ilicitanos se vieron obligados a llevar a moler su trigo a otros pueblos de la zona. Del casal que proyectaba construir F. Maquivar en el azud de la acequia de Mislata, en la Huerta de Valencia, el año 1776 , se decía que resultaba indispensable para los vecinos del municipio de Cuarte, «a quienes relevará de la molestia y perjuicios que sufren de hir a hazer la molienda a otros pueblos bastante distantes», puesto que las familias de Mislata, «en tiempo de escases se ven precisados el hir a moler a [...] Sueca y Buñol», a una treintena de kilómetros. Para conseguir que se le estableciera un casal en el término de la Fuente de la Higuera, F. Biosca aducía, en el año 1807, que evitaría a los 600 habitantes de este núcleo «irse a dos y más leguas de distancia a moler [...] a Moixent, Vallada, Canals, Ontinyent y otras partes, la más cercana a 3 horas de camino». Todavía a mitad del siglo XIX, resultaba habitual que recuas de mulas llevaran a moler a Crevillente trigo del Bajo Segura o que desde la zona alicantina de la Marina se acudiera a los lejanos casales de las comarcas de la Safor o la Ribera del Júcar. Además de incomodidades, el déficit de este servicio incrementaba el precio de la harina, como ocurrió en la huerta de Alicante el año 1731, cuando los 14 molinos del río Montnegre no pudieron funcionar debido a la falta de caudales hídricos. ${ }^{29}$

Por contra, la liberalización del sector, el incremento de instalaciones molineras y la aparición de grandes fábricas de harina - caracterizadas por su enorme capacidad productiva - provocaron, desde mitad del Ochocientos, una sobreoferta que forzó a muchos molinos a tener que reconvertirse o verse obligados a cerrar. ${ }^{30}$

\subsection{Reconversiones productivas de casales y la estrategia de simultanear diversos usos}

A lo largo de la etapa estudiada, fue frecuente que un molino - o alguna muela - dejara de trabajar en una actividad para dedicarse a otra que gozaba de mayor demanda, sobretodo cuando un casal se reformaba o reedificaba. Es fácil, pues, entender que un mismo molino fuera - sucesivamente - harinero, arrocero, pañero, etc. La mayoría de reconversiones se concentran en el tránsito de los tiempos medievales al Antiguo Régimen así como en el

28 Madoz, 1982: voz Carbó; Expediente...; Ferri, 2000: 456; PerIs, 2009.

29 Peris, 2000: 289; Archivo de la Acequia Real del Júcar, legajo 31, nº 15; Guinot, 1999: 70; GuinOt, 2003: 172 y 206; Ferri, 2000: 463; Archivo del Reino, Bailía-E, $\mathrm{n}^{\circ} 1.261$, ff. 3v-4 y expediente 2.374, f. 26; Bailía-E2, expediente 956, ff. 29v-30v. El precio de pan experimentó «acusadas alzas al tener que desplazarse los naturales de la Huerta a lugares distantes varias leguas para efectuar sus moliendas» (A.M. de Alicante, Información [...] sobre los perjuicios que se experimentan [...] por la falta de agua [...]. Año 1731, legajo 22, expediente 31; cit. Alberola, 1994: 93).

30 Incluso en comarcas acostumbradas a sufrir un grave déficit durante el Antiguo Régimen, como el Camp de Morvedre, se pasó a la situación contraria en el Ochocientos. En zonas del interior donde menguó la población (como los partidos judiciales de Ayora, Chelva o El Villar) algunos casales dejaron de moler debido fundamentalmente a la falta de clientes. 
dinámico siglo XVIII, centuria durante la cual se produjeron importantes novedades legislativas, notables cambios en la estructura del poblamiento y relevantísimas mutaciones económicas. La expansión arrocera propició que los molinos harineros incorporaran muelas para descascarillar arroz o que algunos casales llegaran a transformarse en arroceros. La metamorfosis resultaba fácil gracias a la técnica que permitía blanquear el arroz haciéndolo pasar entre dos muelas horizontales en lugar del sistema medieval, consistente en picarlo mediante mazos que seguían un movimiento vertical de alzado y caída (los ejemplos abundan en la Ribera, Valldigna-Safor, la Costera y otras comarcas valencianas que contaban con dilatados marjales litorales). De la misma manera, la reconversión de batanes en molinos papeleros tuvo gran entidad en las comarcas alicantinas de l'Alcoià y la Vall d'Albaida durante la segunda mitad del Setecientos. ${ }^{31}$

Un aspecto poco comentado es la estrategia productiva consistente en simultanear la actividad harinera con la arrocera o la textil en un mismo casal. De esta manera, se conseguía un óptimo aprovechamiento del salto y de las instalaciones, pues se lograba dar una respuesta idónea a la estacionalidad de la demanda y de los caudales impulsores, al tiempo que se propiciaba una excelente adaptación a la coyuntura económica. El blanqueo del arroz y la molienda de trigo tenían diferentes picos de demanda. El descascarillado del arroz se concentraba entre septiembre y noviembre, para menguar bastante durante el resto del año. Por el contrario, la temporada de máximo trabajo harinero era la segunda parte del otoño y todo el invierno, cuando había abundancia de caudales hídricos, apenas se requería regar los campos y se podía moler mayor cantidad de trigo porque las bajas temperaturas permitían que la harina tardara al fermentar o agusanarse. Disponer en un mismo casal de muelas harineras y arroceras fue, pues, una buena opción allí donde la estructura de cultivos incluía este cereal asiático o los flujos comerciales posibilitaban la llegada de suficiente arroz. En el caso de los molinos harineros y pañeros, la razón que estimuló el doble uso fue la irregularidad de la corriente impulsora: obtener buena harina en molinos horizontales requería una corriente capaz de hacer girar las muelas a la velocidad adecuada; cuando faltaba agua y el giro era demasiado lento, se podía seguir abatanando sin problemas, como se documenta en el molino que se proyectaba construir en Bañeres el año 1768 ( «cuando no pueda servir para moler, servirá para abatanar en aquellos tiempos que tenga poca agua»). ${ }^{32}$

\section{La evidente continuidad tecnológica}

Gracias a V. M. Rosselló, T. F. Glick, S. Selma y L. P. Martínez Sanmartín sabemos de la contundente hegemonía de los molinos harineros de rueda horizontal que impulsaban las muelas con el giro del rodezno conseguido mediante agua a presión. El predominio fue abrumador, tanto desde el punto de vista cronológico (desde la época islámica a la etapa contemporánea) como geográfico (tanto en microsistemas de montaña como en las grandes huertas). La prevalencia se explica por la versatilidad ecológica, económica y social de este modelo tecnológico. Nadie discute ya la alta eficiencia energética, que se conseguía haciendo trabajar el chorro a presión contra los álabes de una rueda horizontal, gracias a la altura del agua acumulada en la acequia o a la columna acopiada en el interior del cubo. L. P. Martínez explicó que estas ruedas horizontales eran simples, robustas, eficientes y versátiles, permitiendo rodar tanto a pequeños molinos con caudales

31 En la acequia Real de Alzira, sólo había 7 molinos harineros el año 1765, mientras que 2 eran arroceros y 11 casales mixtos (Peris, 2000: 341-342; Cavanilles, 1795-97, vol. I: 196; Branchat, 1784, vol. I: 277 y 290 291).

32 PERIS, 2003: 104-131; PÉREZ, 1999: 56. 
escuálidos como hacer trabajar grandes instalaciones molinares allí donde la corriente era lo suficientemente abundante y regular. El problema de la insuficiente velocidad de giro de la muela volandera (si hubieran funcionado con la corriente demasiado lenta, propia de los cursos fluviales meandrizantes, de baja pendiente, como lo son los ríos valencianos en su cuenca baja) se resolvía haciendo circular el agua por una acequia con la pendiente idónea para que velocidad de la muela — idéntica al giro de la rueda impulsora - fuera la deseada. Los rodeznos horizontales resultaban válidos tanto para los pequeños molinos rurales como para grandes instalaciones periurbanas; la única cuestión consistía al saber escoger en cada caso la mejor opción técnica: canal abierta o cubo, con balsa o sin ella, en conjuntos molinares o en forma de casales dispersos emplazados estratégicamente dentro de las redes de canales de riego, etc. ${ }^{33}$

También hubo en tierras valencianas unas pocas rueda verticales que accionaron batanes textiles, molinos papeleros y martinetes, especialmente en barrancos molinares. Algunas remontan su existencia a tiempos medievales, pero la mayoría fue fruto de la expansión dieciochesca. Con todo, la existencia de alguna de estas ruedas verticales funcionando en fechas tardías sobre caudalosas acequias fluviales, dispuestas para impulsar molinos arroceros y harineros, desmiente que la marginalidad de este tipo de aprovechamiento energético de las aguas tuviera como principal causa resultar demasiado perturbadora del reparto consuetudinario de caudales pactado previamente por los diversos colectivos de regantes (PERIS, 2000: 292-293).

Los molinos valencianos experimentaron pocos cambios en la tecnología base desde el siglo XIII hasta mitad del Ochocientos: siguió utilizándose el modelo de rueda horizontal, impulsada a presión, que transmite la rotación a la muela volandera mediante un robusto eje vertical. Pero existieron innovaciones que deben contemplarse, tanto en la manera de captar el agua como en lo que se refiere a los mecanismos que transmitían la energía hasta las muelas. Dignas de mención resultan las almenaras o derramadores (un paso junto a los cárcavos o una acequia que circuía el casal), que se multiplicaron hasta resultar obligatorios al final del Antiguo Régimen y que conseguían minimizar los perjuicios a otros usuarios al tiempo que propiciaban el óptimo rodar del molino (facilitaban templar el giro de las muelas y la limpieza de los cárcavos, permitían trabajar durante las crecidas fluviales, etc.). Por lo que respecta a las mejoras en el propio casal, la incorporación del cubo, una novedad medieval, ya estaba bien extendida cuando llegaron los conquistadores feudales en el siglo XIII. Hubo otras novedades discretas, pero destacables. Una relevante afectó al punto sobre el que se apoya todo el eje motriz: el cambio de huevos de piedra, propios de los molinos hispanomusulmanes, por dados y agujas metálicas (de hierro o bronce) redujeron la pérdida de energía por fricción. Las muelas también experimentaron metamorfosis evolutivas dignas de mención: se hicieron de un diámetro mayor y las autóctonas, de peor calidad, fueron sustituidas por las catalanas en el siglo XVIII y por las francesas en el Ochocientos. Otra novedad a tener en cuenta fue la facilidad de uso del tapón de la saetia y del gancho de arrancar, que permitieron regular con comodidad la fuerza del chorro de agua que incidía sobre los álabes y controlar mejor la velocidad de rotación de las muelas (entre 80-90 giros por minuto las harineras y 100-120 las arroceras). La tarea de nivelar la muela volandera, así como el método para regular la distancia entre ésta y la muela solera — de la que dependía la calidad de la harina - , dejaron de depender de la habilidad del

33 Los molinos de rueda horizontal y chorro a presión llegaban a aprovechar el $75 \%$ del potencial energético (MarTínez, 1992: 108-119; MarTíneZ, 1993: 38-43). Es obvio que trabajaban a presión los molinos de cubo, pero también los de canal abierta ubicados en las grandes huertas, que aprovechaban el peso del agua acumulada en el cauce de la acequia y hacían que la entrada de agua hacia la rueda fuera cada vez más estrecha, hasta convertirse en un chorro que golpeaba los álabes con gran fuerza. 
molinero y pasaron a ser unas maniobras facilitadas por artilugios mecánicos (el alzador permitió, mediante un volante roscado, subir o bajar todo el sistema transmisor, haciendo que la separación aumentara o se redujese con facilidad y total precisión).

Los préstamos tecnológicos menudearon entre las diversas modalidades de establecimientos que empleaban la energía motriz de las aguas. Así, por ejemplo, la tecnología de los batanes textiles se adaptó para picar arroz en tiempo medievales o acabó derivando en molinos papeleros, unas instalaciones que se multiplicaron desde mitad del siglo XVIII.

\section{Inviabilidad del monopolio banal del feudalismo clásico: la mercantilización de la molinería valenciana}

Las tendencias historiográficas que van de Marc Bloch a Miquel Barceló comparten el acierto de considerar que las opciones tecnológicas no fueron decisiones neutras, ya que se adoptaron en función de los intereses sociales dominantes. Por lo que respecta al uso energético de las aguas, tienden a postergar la pugna entre la monarquía y los señores, disputándose la exclusividad sobre el aprovechamiento de las corrientes hídricas y la facultad de edificar casales, y tratan de focalizar el análisis en el monopolio de uso. Postulan que la capacidad de los feudales por reorganizar el sistema agrícola en favor de cultivos de secano, así como de obligar los vasallos a acudir a moler al casal señorial, fueron premisas obligadas - en un contexto autárquico - para llevar a cabo un control exhaustivo de los excedentes campesinos y expoliar con rapacidad a las comunidades rurales (Barceló, 1988). Desde la perspectiva valenciana de los siglos XIII-XIX, sin embargo, resulta obligado matizar estas aseveraciones.

De entrada, la capacidad de establecer molinos siempre fue compartida por la corona y los señores. Factores como la tardía feudalización del territorio, la pujanza política de la monarquía, la gran entidad de ciudades y villas reales, etc., propiciaron que el principio jurídico de la naturaleza pública de las aguas tuviera mayor fuerza en el País Valenciano. No obstante, durante los siglos XIV y XV, infinidad de señores aprovecharon las debilidades de la corona para edificar molinos sin el preceptivo establecimiento del Real Patrimonio. Y las cartas pueblas posteriores a la expulsión morisca de 1609 contribuyeron a reforzar los derechos privativos y prohibitivos de barones e instituciones eclesiásticas sobre casales molineros, que pasaron a ser considerados, globalmente, «regalías propias de los señores». ${ }^{34}$ Coexistieron, pues, molinos materializados por el ejercicio de regalía de la corona y otros edificados en virtud de aplicar la jurisdicción baronal (las usurpaciones fueron especialmente numerosas durante el siglo XVII y la primera mitad del Setecientos). Únicamente a partir de 1760-1770, el Real Patrimonio se esforzó para hacer efectivos los derechos enfitéuticos derivados de la existencia de molinos (canon anual y el luismo originado por cada alienación del inmueble), tanto en los realengos como en los señoríos donde los titulares se habían arrogado - sin que ningún privilegio real autorizara a ello- la facultad privativa y prohibitiva. ${ }^{35}$

34 Reconocían al señor el derecho de establecer molinos así como obligar a los vasallos a moler en el establecimiento señorial. La carta puebla de Bélgida (10-VII-1616), ordenaba que el «senyor se reserva totes les regalies [...], per quant tots temps són estades sehues; ço és: molí, tendes, forn, almàcera [..., etc.]; y que no se'n facen de noves [...] que no sien del senyor. Ítem [...] que ningú dels vassalls puga, havent-hi aygua bastant en lo molí, [...] anar a moldre fora [...] sots les penes a dit senyor ben vistes» (SENDRA, 1998: 24-25, 80-81 y 94-95). Durante el siglo XVII apenas se mencionan establecimientos realizados por la Bailía Real, hecho que responde tanto al descenso demográfico experimentado en el conjunto del territorio valenciano como al conocido proceso de usurpación de regalías por parte de los señores (BRANCHAT, 1784: vol. I, 253 y 317-318).

35 Vicente Branchat defendió - con manifiesta parcialidad - la tesis que «siempre se ha considerado la facultad de establecer estos artefactos regalía propia de la Soberanía, reservada a la Corona», tanto en los realengos como en los territorios de señorío (BRANCHAT, 1784, vol. I: 243-262). 
El monopolio de uso (elemento clave en la tesis más prestigiosa del feudalismo clásico) tuvo una vigencia tenue en tierras valencianas, ya que nunca existió en las áreas de realengo y se aplicó con laxitud en la mayoría de señoríos, donde fue muy difícil de alcanzar y mantener, como puso de relieve V. Rosselló. El sistema feudal valenciano nunca funcionó al margen del mercado. Al contrario, la relevancia alcanzada por las ciudades y de los subsiguientes intercambios comerciales que las vinculaban entre sí, con el mundo rural y con territorios lejanos explica que unos fluidos nexos mercantiles impregnasen a todo el reino. La libertad de molienda existió en los dilatados realengos valencianos desde una fecha tan temprana como el año 1283, cuando el Privilegium Magnum de Pedro III, transformado después en fuero ( «De almaceris te molendinis te quae quis possit ubico molere»), concedió el derecho a moler donde mejor acomodara.

En igualdad de condiciones por lo que respecta a la calidad de la harina y la tasa de maquila cobrada por el servicio, los clientes tendieron a acudir a los molinos próximos - fuera cual fuese el rango social del el propietario - por cuestión de pura comodidad. El protagonismo urbano, la relevancia de los flujos de importación de cereales, así como la propiedad de numerosos casales por parte de grupos acomodados no señoriales explica que el grueso de la molinería valenciana no estuviera vertebrada por la explotación feudal, sino que tratara de obtener beneficios siendo competitivos respecto a otros establecimientos próximos. Los señoríos valencianos debieron compaginar el teórico monopolio de uso y el impacto de las fuerzas del mercado. En los ubicados en el hinterland de las principales ciudades y villas reales siempre resultó muy difícil que los titulares - nobles o instituciones eclesiásticas - hicieran efectivo el monopolio de uso que les reconocía la jurisprudencia. El control señorial sobre los molinos hidráulicos se debilitó en tierras valencianas durante las postrimerías medievales y el Quinientos, de resultas de abandonar la gestión directa por el cómodo establecimiento enfitéutico o el arrendamiento de casales, de alienar molinos en momentos de estrechez o bien de aceptar que la corona estableciera este tipo de instalaciones de aprovechamiento energético de las aguas y los municipios las construyeran. Por contra, las cartas pueblas promulgadas entre 1611 y 1614 permitieron a muchos señores apropiarse de atribuciones jurisdiccionales que nunca antes habían tenido o habían dejado prescribir, entre ellas la regalía de los molinos. ${ }^{36}$ Las dificultades para hacer efectivo el monopolio de uso molinero en una economía tan abierta como la valenciana, estimularon la mercantilización de la molienda. En la mayor parte de señoríos se generalizaron las situaciones híbridas y se hizo borrosa «la frontera entre una molinería nítidamente feudalizada y una puramente comercial». Abundaron las situaciones difíciles de encajar en los paradigmas historiográficos más consagrados, como por ejemplo que clientes de realengo acudieran como parroquianos a los casales molineros de baronías próximas, libremente y porque les convenía, tal como V. Branchat documenta que se producía en la zona de Sagunto en 1756 y Alcoi en 1775, o T. F. Glick y L. P. Martínez informan que ocurría en muchas villas reales valencianas con el propósito de esquivar las restricciones impuestas por los gremios o evitar pagar onerosas sisas municipales. ${ }^{37}$

Síntoma elocuente del cariz mercantil que la actividad molinera mantuvo en los señoríos es la generalización del régimen de arrendamiento de los casales por pocos años y la rareza - y transitoriedad - de la explotación directa por parte de los titulares. Los señores

36 Únicamente se mantuvo un monopolio de uso bastante completo en una minoría de señoríos: en algunas zonas montañosas del interior, determinados poderes feudales, fuertes desde el origen y particularmente bien organizados, consiguieron imponer un control efectivo (es el caso, por ejemplo, de la cabecera del río de la Cenia, señoreada por el monasterio de Benifassá; Arasa, ForCadell y Michavila, 2000: 400-401).

37 Branchat: 1784-86, vol. I: 262 y 267 así como vol. III, 154-155 y documento IX; GLick-MartíneZ, 2000: 44-47 y 79-80; CísCAR, 1977: 228-235; SENDRA, 1998: 64, 80-81 y 94-95; OLIVER, 1983: 19. 
perseguían unas ganancias fáciles arrendando casales en lugar de pretender una expoliación de la comunidad campesina por la vía de la renta feudal (no emplearon el molino como instrumento de fiscalidad que dificultara los fraudes en las particiones de frutos). Incluso en los casos en que el monopolio llegó a ser efectivo, pretendía más bien aprovechar al máximo el potencial productivo de las instalaciones - premisa para alcanzar arrendamientos más lucrativos - en lugar de llevar a término un supuesto control de la producción campesina mediante la obligación de acudir al molino señorial. La incidencia del mercado fue incluso mayor en el caso de artilugios hidráulicos que tenían una tarea distinta a transformar los cereales en harina, como es el caso de los batanes textiles, ingenios azucareros, forjas y molinos papeleros, instalaciones que siempre funcionaron vinculadas a redes comerciales de largo alcance. Prueba elocuente que los molinos no fueron el instrumento esencial de explotación campesina, es que las quejas contra el monopolio de la moltura nunca formaron parte del núcleo central de las reivindicaciones antiseñoriales.

Más allá del afán señorial de alcanzar un monopolio de uso (difícil de conseguir en un contexto tan poco autárquico como lo fue la economía valenciana de los siglos XIIIXVIII), hubo otras apetencias que pretendieron restringir la libertad de molienda, como las estrategias practicadas por sagas de molineros, gremios y municipios con la finalidad de disponer de una clientela cautiva, obligada a acudir a unos casales concretos y bajo determinadas condiciones.

Es bien sabido que la agremiación de molineros siempre mantuvo los objetivos de frenar las innovaciones técnicas y limitar el número de competidores. ${ }^{38}$ Peor conocidos son los anhelos de controlar la actividad de producción de harina manifestada por bastantes municipios. Uno de los casos mejor documentados es Villareal, núcleo castellonense donde, desde el siglo XV hasta mitad del XIX, el ayuntamiento sostuvo una política que perseguía dominar el sector (Doñate Sebastiá informa como el proceso se inició con la compra del casal más conflictivo por parte del consejo local en el año 1369). E. Guinot y S. Selma aluden al interés de las instituciones municipales de Elche por poseer molinos y evitar que se edificaran otros establecimientos en los señoríos del Bajo Vinalopó. Y el jurista Vicente Branchat informó como el ayuntamiento de Alzira venía obligando, en las décadas centrales del siglo XVIII, a los panaderos de esta importante villa a moler en el molino municipal, cosa que perjudicaba sobremanera a los propietarios del resto de molinos existentes en el término. Otra manifestación de la tendencia monopolística vigente en el sector es la formación de sagas de propietarios y de familias de molineros que restringían la concurrencia en el mercado de la moltura. F. Sendra documenta esta propensión en la comarca de la Vall d'Albaida durante los siglos XVI y XVII, donde unas pocas familias (Olzina, Sancho, Arbuxec, Miralles, Soler, Turrón y Golfo) consiguieron controlar el sector, al acumular la propiedad de diversos casales. M. Ferri menciona ejemplos de este tipo de restricciones por parte de linajes de molineros que ejercieron en la zona de Sagunto durante la crisis del Antiguo Régimen. ${ }^{39}$

38 La normativa gremial del sector de la molinería solía enmascararse entre la normativa municipal hasta que este tipo de disposiciones fueron confirmadas por la corona en los siglos XVIII o XIX. Las Ordenanzas del Gremio de Molineros de Sagunto, renovadas el año 1832 «tomaban especial cuidado en impedir aquellas acciones individuales que afectaran a los beneficios del colectivo [...]; se prohibía explícitamente prácticas como asociarse a mercaderes que fiaran el trigo a labradores pobres o horneros, o bien premiar de ninguna manera al «hornero, remasador ni otro sujeto particular» por acudir a moler en un molino concreto» (FERRI, 2000: 454-455; MESADO, 1987: 276). De las ordenanzas del Gremio de Molineros de la ciudad de Valencia, de los años 1605, 1754 y 1776 , que sirvieron de referencia para otras muchas poblaciones valencianas, se conservan ejemplares impresos en el Archivo Municipal de Valencia (Fondo Serrano Morales, 348, $\mathrm{n}^{\circ}$ 6878)

39 Doñate, 1990: 102-121; Guinot: 2003, 164; BRANCHAT, 1784-86: I, 262 y III, 152-154; SENDRA, 1998 : 90-91 y 109-110; FERRI, 2000: 455-456. 


\section{Conclusión}

La sólida perspectiva de análisis social de los molinos de agua que arranca de Marc Bloch ha sido muy fecunda, en especial porque ha puesto de manifiesto que bajo las opciones económicas y técnicas no sólo hay determinismo geográfico sino que subyacen fuertes implicaciones sociopolíticas. Seria deseable, sin embargo, que el estudio de los molinos hidráulicos dejara de ser una temática que interesa casi exclusivamente a los medievalistas, ya que este rasgo historiográfico comporta el predominio de ciertas maneras de enfocar el tema que resultan peligrosas, en especial la supervaloración relativa del el uso energético de las aguas, muy por encima del que ha conseguido y merece el regadío. Se ha llegado al extremo - a mi entender exagerado - de reconocer a estos ingenios la capacidad de reorganizar el conjunto de la producción agrícola en las sociedades feudales (Barceló), o se ha querido hacer de los casales la clave explicativa capaz de revelar los criterios de diseño y la evolución de los hidrosistemas (Martínez Sanmartín). Además, emplear los microsistemas de montaña en zonas semiáridas como marco de análisis prioritario ha propiciado que se exagere la conflictividad existente entre regadío y molienda, considerándola estructural y determinante, cuando lo que hubo fue más bien una complementariedad de usos (PERIS, 2012). Por último, resulta obvio que centrar el estudio en la dicotomía radical de modelos conceptuales, pequeño molino «campesino» horizontal (altomedieval o hispanomusulmán) versus gran molino «señorial» de rueda vertical («feudal»), es más discutible y arriesgado que plantear una múltiple referencia que incluya la calidoscópica variedad de casales del Antiguo Régimen o contemporáneos y las respectivas funciones económicas y sociales que fueron cumpliendo, adaptándose a sucesivas etapas evolutivas.

No se trata de hacer ningún reproche a aquellos que tienen el mérito indiscutible de habernos estimulado a estudiar el sector de la molinería - en todo caso sería al colonialismo que las historiografías atlánticas proyectan sobre los territorios mediterráneos-, sino de señalar la capacidad de modernistas, contemporaneistas y geógrafos de enriquecer el análisis, haciendo posible una panorámica más nítida en la muy larga duración plurisecular. La perspectiva social de estudio de los molinos es irrenunciable, pero hay que mejorarla despojándola de rigideces y enriqueciéndola con datos que muestran complejidades insospechadas, como que los estamentos privilegiados no monopolizaron la propiedad de casales (fue un sector repartido entre los diversos grupos que constituían las oligarquías locales), o bien que campesinos, municipios, burgueses y señores llegaron a emplear los molinos como instrumentos en una estrategia que no perseguía otra cosa que conseguir un mayor caudal para regar sus campos. ${ }^{40}$

\section{Referencias bibliográficas}

ALBEROLA ROMÀ, A. (1994). El pantano de Tibi y el sistema de riegos en la huerta de Alicante. Alicante: Instituto de Cultura Gil-Albert.

ARASA, J. FORCADELL, T. y I. MICHAVILA (2000), «Els litigis per l'ús de l'aigua. El sistema hidràulic del riu de la Sénia a l'època moderna». En: GLICK-GUINOTMARTÍNEZ (eds.). Els molins hidràulics valencians. Tecnologia, història i context social. Valencia: Alfons Magnànim, p. 389-404.

40 El molino hidráulico no puede contemplarse limitándonos a considerarlo un instrumento de opresión feudal. Adquirir o edificar molinos fue una vía inversora que ninguno de los sectores sociales con disponibilidad de capital menospreció nunca. Sorprendería la entidad alcanzada por los municipios forales o los ayuntamientos borbónicos como propietarios de molinos, tal y como corrobora el hecho que el arriendo de instalaciones harineras fue una saneada fuente de ingresos para las arcas municipales hasta que la desamortización de Madoz cambió radicalmente el panorama de mediados del siglo XIX (PerIS, 2009). 
BARCELÓ, M. et alii (1988). Arqueología medieval en las afueras del «medievalismo». Barcelona: Crítica.

BOSCH JULIÀ, M. (1866). Memoria sobre la inundación del Júcar... Madrid: Imprenta Nacional.

BRANCHAT, V. (1784-86). Tratado de los derechos y regalías que corresponden al real patrimonio del reyno de Valencia, 3 vols. València: Imprenta de J. y T. d'Orga.

CASTILlO SANZ, J. (1997). Els conflictes d'aigua a la Safor medieval. Gandía: CEIC Alfons Vell.

CAVANILLES, A. J. (1795-97). Observaciones sobre la historia natural, geografía, agricultura, población del Reyno de Valencia, 2 vols. Madrid: Imprenta Real.

CÍSCAR PALLARÉS, E. (1977). Tierra y señorío en el País Valenciano (1570-1620). València: Del Cénia al Segura.

CÍSCAR PALLARÉS, E (1997). La Valldigna siglos XVI y XVII. Cambio y continuidad en el campo valenciano. València: Diputació de València.

DOÑATE SEBASTIÀ, J. M. (1990). «Molinería y molinos en la Plana de Castellón». Boletín de la Sociedad Castellonense de Cultura, núm. 66, p. 99-123.

FERNÁNDEZ TRABAL, J. (2004). «Les indústries rurals». En: E. GIRALT RAVENTÓS (dir.). Història Agrària dels Països Catalans. Vol. II. Barcelona, Fundació Catalana de la Recerca, p. 361-395.

FERRI I RAMIREZ, M. (2000). «Molins i moliners al segle XIX. Notes entorn al cens de molins de la província de València de 1847». En: GLICK-GUINOT-MARTÍNEZ (eds.). Els molins hidràulics valencians..., p. 451-482.

FERRI I RAMÍREZ, M. (2001). «El Camp de Morvedre als segles XVIII i XIX. Dos segles d'un paisatge agrari canviant». En DD.AA.. Horta i Secà al Camp de Morvedre. Cartografies Hidràuliques. Segles XVIII i XIX. Sagunto: Ayuntamientos de Algímia y Quart de les Valls, p. 7-26.

FURIÓ, A. i MARTÍNEZ, L. P. (1994). «Assuts i molins sobre el Xúquer en la Baixa Edat Mitjana». En: IV Congreso de Arqueología Medieval Española «Sociedades en transición». Actas: Alicante, 4-9 de octubre de 1993. Vol. III, Alicante, Generalitat Valenciana, Asociación Española de Arqueología Medieval y Diputación de Alicante, p. 575-586.

GIL OLCINA, A. (1992): «Las políticas hidráulicas del Reformismo Ilustrado». En A. GIL OLCINA y A. MORALES (eds.). Hitos históricos de los regadios españoles. Madrid, Ministerio de Agricultura, Pesca y Alimentación.

GLICK, T. F. (1988). Regadío y sociedad en la Valencia medieval. València: Del Cénia al Segura.

GLICK, T. F. (1990). «Molins d'aigua a L'Horta medieval de València. Observacions a un article de Vicenç. M. Rosselló», Afers, núm. 9, p. 9-22.

GLICK, T. F., GUINOT, E. y L. P. MARTÍNEZ, eds. (2000). Els molins hidràulics valencians. Tecnologia, història i context social. Valencia: Institució A. Magnànim.

GLICK, T. F. i L. P. MARTÍNEZ (2000). «La molineria hidràulica valenciana. qüestions obertes». En: GLICK-GUINOT-MARTÍNEZ (eds.). Els molins hidràulics valencians..., p. 7-28.

GUINOT RODRÍGUEZ, E. (2000). «Molins andalusins i molins feudals: l'ordenació del sistema hidràulic baix-medieval del riu de la Sénia». En GLICK-GUINOT-MARTÍNEZ (eds.). Els molins hidràulics valencians..., p. 193-228.

GUINOT RODRÍGUEZ, E. y otros (1999-2003). Col·lecció Camins d'Aigua. València, Conselleria d'Agricultura Generalitat Valenciana; I. La Real Acequia de Moncada, 1999; II. La Acequia Real del Júcar, 2000; III. Las acequias de la Plana de Castellón, 2001; IV. Las acequias de Elche y Crevillente, 2003. 
JAUBERT DE PASSÀ, F. J. (1844). Canales de riego de Cataluña y Reino de Valencia, leyes y costumbres que los rigen; reglamentos y ordenanzas de sus principales acequias, 2 vols, València: Imprenta Benito Monfort (reed. Madrid: MAPA-Universitat de València, 1991).

MADOZ, P. (1982). Diccionario Geográfico-Estadístico-Histórico de Alicante, Castellón y Valencia, 1845-52 (facsímil parcial de la obra de 1845-52, Valencia: Alfons Magnànim).

MANGUE I ALFÉREZ, I. (2000). «Séquies i molins de València: la séquia de Rascanya, hidraulisme al marge esquerre del Túria». En GLICK-GUINOT-MARTÍNEZ (eds.). Els molins hidràulics valencians...., p. 405-450.

MARTÍNEZ SANMARTÍN, L. P. (1992). «Estructura social y cambio tecnológico. Una crítica a los determinismos tecnológicos y economicista en la historia de la técnica», Arbor, núm. 561, p. 103-131.

MARTÍNEZ SANMARTÍN L. P. (1993). «La lluita per l'aigua com a factor de producció. Cap a un model conflictivista d'anàlisi dels sistemes hidràulics valencians». Afers, núm. 15 , p. 27-44.

MARTÍNEZ SANMARTÍN, L. P. (2005). «Els molins com a clau de l'articulació de l'Horta medieval de València. La sentència de 1240 entre moliners d'Alaxar i la comunitat de Rascanya». Afers, núm. 51, p. 369-396.

MESADO OLIVER, N. (1987). «Molinos en Burriana», En DD.AA.: Burriana en su Historia, vol. I. Burriana: Ayuntamiento, p. 275-299.

MIRA JÓDAR, A. J. (2000). «La organización de la red molinar en la Vall d'Albaida y l'Alcoià a finales de la edad media. Infraestructura industrial, desarrollo económico y fiscalidad». En: GLICK-GUINOT-MARTÍNEZ (eds.). Els molins hidràulics valencians...., p. 229-272.

OLIVER NARBONA, M. (1983). Molinos harineros de agua. Alcoi, Universitat d'Alacant.

PALANCA, F. (1986). Del gra al pa. Els molins. Valencia, Museu Etnologia i Diputació València.

PÉREZ MEDINA T. V. (1999). Los molinos de agua en las comarcas del Vinalopó (15001840). Petrer, Centre d'Estudis Locals de Petrer.

PÉREZ MEDINA, T. V. (2000). «Els molins il·lustrats de les comarques del riu Vinalopó». En GLICK-GUINOT-MARTÍNEZ (eds.). Els molins hidràulics valencians...., p. 359-388.

PERIS ALBENTOSA, T. i ROMERO GONZÁLEZ, J. (1992). «Usos, distribució i control de l'aigua». Geografia General dels Països Catalans, II. Barcelona, Enciclopèdia Catalana, p. 186-277.

PERIS ALBENTOSA, T. (1992a). Regadío, producción y poder en la Ribera del Xúquer. La Acequia Real de Alzira, 1258-1847. Valencia: Conselleria d'Obres Públiques i Confederació Hidrogràfica del Xúquer.

PERIS ALBENTOSA, T. (1992b). «Toponimia y tecnología hidráulica en la Acequia Real de Alzira o del Xúquer», Al-gezira, núm. 7, p. 113-211.

PERIS ALBENTOSA, T. (1995) «La evolución de la agricultura valenciana entre los siglos XV y XIX. Rasgos cualitativos y problemas de cuantificación», Revista de Historia Económica, XIII, n ${ }^{\circ}$ 3, p. 473-508.

PERIS ALBENTOSA, T. (2000). «Aigua i molins en un macrosistema fluvial valencià. La molineria a la Ribera del Xúquer, segles XIII-XIX». En GLICK, T. F., GUINOT, E. y L. P. MARTÍNEZ (eds.): Els molins hidràulics valencians. Tecnologia, història $i$ context social. Valencia: Institució A. Magnànim, p. 273-357.

PERIS ALBENTOSA, T. (2003). La terra de l'arròs i les moreres. Alzira, Bromera.

PERIS ALBENTOSA, T. (2009). Els molins d'aigua valencians (segles XIII-XIX). Estat de la qüestió i propostes d'anàlisi. Inédito. 
PERIS ALBENTOSA, T. (en prensa): «Les qüestions per l'aigua al País Valencià durant l'etapa feudal: l'exemple dels molins», comunicación al V Congrés d'Història Agrària..., Barcelona, 15-17 diciembre 2010, en vías de publicación en Estudis d'Història Agrària, Barcelona, 2012.

PLANES I ALBETS, R. (2008). «Indústries rurals: la molineria de cereals, les almàsseres, el sucre». En: E. GIRALT RAVENTÓS (dir). Història Agrària dels Països Catalans, vol. III. Barcelona: Fundació Catalana de la Recerca, p. 235-261.

RIBES IBORRA, V. (1995). La industrialització de la zona de Xàtiva en el context Valencià. Xàtiva: Ayuntamiento de Xàtiva.

ROMÁN MILLÁN, I. (2000). El regadío de Vila-real durante los siglos XIII-XV. Villareal, Ayuntamiento y Comunidad de Regantes.

ROSSELLÓ I VERGER, V. M. (1989a). «El control de l'aigua (poder i tradició)». En SAN MARTÍN, A. (ed.). Els espais del poder. València: Universitat de València, p. 67-89.

ROSSELLÓ I VERGER, V. M. (1989b). «Els molins d'aigua de l'Horta de València». En: DD.AA.. Los paisajes del agua... Valencia-Alicante, Universidades de Valencia y Alacant, p. 317-345.

ROSSELLÓ I VERGER, V. M. (1993). «Molins fariners d'aigua. Reflexions no polèmiques d'un geògraf». Afers, núm. 15, p. 45-51.

SANCHO A. i S. MONLEÓN (1860). Dictamen facultativo sobre el proyecto formado por don Juan Bautista Peyronet para canalizar el río Júcar y poder fertilizar la provincia de Alicante. Valencia: Imprenta J. M. Ayoldi.

SELMA CASTELL, S. (1993). «Molins i rodes: entorn d'una discussió desafortunada». Afers, núm. 15, p. 11-26.

SELMA CASTELL S. (1994). Els molins d'aigua medievals a Sharq al-Andalus. Aproximació a través de la documentació escrita dels segles X-XIII, Onda, Ayuntamiento.

SELMA CASTELL, S. (2000). «De la construcció islàmica al casalici modern: l'evolució del molí hidràulic valencià». En GLICK-GUINOT-MARTÍNEZ (eds.). Els molins hidràulics valencians... 2000, p. 101-164.

SENDRA BAÑULS, F. (1998). Molins d'Aigua a la Vall d'Albaida. Ontinyent: Caixa d'Estalvis.

TARAÇONA, P. (1580). Institucions dels Furs y Privilegis del Regne de València... Valencia: Imprenta de P. de Guete. 